\title{
LA FILOSOFÍA KANTIANA DE LA HISTORIA: DIALÉCTICA ENTRE NATURALEZA Y LIBERTAD
}

\author{
Hernán Martínez Ferro* \\ Universidad Pedagógica y Tecnológica de Colombia
}

\section{Resumen}

La filosofía kantiana de la historia: dialéctica entre naturaleza y libertad. El texto pretende mostrar el lugar que ocupan los estudios socio-históricos de Kant, en el sistema de su filosofía crítica. Se sostiene que en la filosofía de la historia, Kant desarrolla una dialéctica entre naturaleza y libertad, con la que puede superar el abismo entre la razón teórica y la razón práctica. Se explicita la relación de complementariedad entre el derecho y la moral como dos legislaciones que cumplen con una tarea común: alcanzar la paz.

Palabras clave: filosofía de la historia, Kant, libertad, paz.

\begin{abstract}
Kant's Philosophy of History: Dialectic between Nature and Freedom. This text aims to show the position occupied by Kant's socio-historical texts within the system of his critical philosophy. It is argued that in Kant's Philosophy of History, he develops a dialectic between nature and freedom, which can bridge the gap between theoretical and practical Reason. This study explores the complementary relationship between law and morality as that of two concepts that carry out a common task: achieving peace.
\end{abstract}

Key Words: philosophy of history, Kant, freedom, peace.

* Profesor Asociado de la Universidad Pedagógica y Tecnológica de Colombia. Miembro del
Grupo de Investigación Filosofía, Educación y Sociedad. Correo-e: martinezferro@ yahoo.es

La filosofía kantiana de la historia - p. 37-55 


\section{Introducción}

Los diversos opúsculos en los que Kant se ocupó de la historia, la política y el Estado, han sido catalogados y así compilados en varias ediciones con el nombre de Filosofía de la historia. Esta catalogación abarca textos que van desde 1784 como la Idea de una historia universal en sentido cosmopolita ${ }^{1}$ y la Respuesta a la pregunta: ¿qué es la ilustración? $?^{2}$, hasta El conflicto de las facultades ${ }^{3} \mathrm{de}$ 1798, pasando por una serie de pequeños y variados ensayos, entre los que destacan la no tan breve Religión dentro de los límites de la mera razón ${ }^{4} \mathrm{de}$ 1793 y La paz perpetua ${ }^{5}$ de 1795.

Debemos tener en cuenta que la expresión "filosofía de la historia" no es de Kant, quien incluso parece haberla eludido. La expresión fue utilizada por Voltaire en su ensayo titulado precisamente La philosophíe de l'histoire publicado en Holanda en 1765; en este texto Voltaire se opone a una historia meramente descriptiva de reyes, dinastías y batallas, y propone una historia razonada de las instituciones, las mentalidades y las tradiciones culturales. ${ }^{6}$ Intereses muy distintos son los que motivan la reflexión kantiana sobre la historia, que no pretende ser una historia razonada de acontecimientos empíricos particulares, sino que le interesa la historia pensada en grande, esto es, entendida como una unidad de la que se pretende encontrar unos principios que sirvan como "hilos conductores" para comprender el "plan de la naturaleza" y descubrir el sentido teleológico de la historia.

La discusión académica en torno a la naturaleza y relación de estos opúsculos con la obra completa del autor ha generado posiciones antagónicas. En la

1 IKANT, Immanuel. "Idea de una historia universal en sentido cosmopolita". En: Filosofía de la historia. México: F. C. E., 1979.

2 KANT, Immanuel. "Respuesta a la pregunta: ¿qué es la ilustración?”. En: Argumentos, Bogotá, No. 14-17, 1986, pp.28-44.

3 KANT, Immanuel. La contienda de las facultades de filosofía y teología. Madrid: Consejo Superior de Investigaciones Científicas/Debate, 1992.

4 KANT, Immanuel. La religión dentro de los límites de la mera razón. Madrid: Alianza, 1969.

5 KANT, Immanuel. La paz perpetua. México: Porrúa, 1972.

6 Voltaire como historiador se destaca con la obra El siglo de Luis XIV, estudio sobre el reinado de ese monarca (1638-1715) y su ambicioso Ensayo Sobre la historia general y sobre las costumbres y el carácter de las naciones (1756), en donde hace un estudio del progreso humano, censura el supra naturalismo y denuncia la religión y el poder del clero. 
recepción que se hizo de los textos bajo la influencia de la llamada Escuela de Marburgo de Hermann Cohen ${ }^{7}$, cuyo interés se centraba casi exclusivamente alrededor de la teoría del conocimiento, estos ensayos son considerados como escritos «ocasionales» e incompatibles con el sistema. No son pocas las catalogaciones que hablan de «obras menores» en las que Kant estaría interesado en dirigirse al gran público o en oponerse a las Ideas para una filosofía de la historia de la humanidad ${ }^{8}$ de Herder, pero en todo caso no harían parte del sistema de la filosofía crítica. Sin embargo, a partir de las últimas tres décadas, el interés por los escritos socio-políticos kantianos ha suscitado una lectura y recepción distinta de los ensayos sobre la historia, llegándose incluso a afirmar que la filosofía de la historia constituye en cierto sentido la más cara y acabada expresión de toda su filosofía. ${ }^{9}$

En este trabajo tomamos partido por esta última lectura, rechazando la opinión según la cual, el pensamiento socio-político de Kant puede ser considerado como reflexiones de última hora sin relación con su obra crítica. Estamos de acuerdo con el comentario de Eugenio Imaz en el prólogo a su traducción española de los textos de Kant:

«A mí me extrañaría mucho que, en cualquier filósofo, sus pensamientos políticos fueran algo así como charlas de sobremesa, más o menos luteranas, donde el sabio se permite el desahogo de hablar ligeramente de cosas, por demasiado cercanas, fuera del alcance perforador de su profunda mirada." 10

Lo que pretendemos con nuestro trabajo es ubicar la problemática de los textos kantianos sobre la filosofía de la historia en el sistema de la filosofía crítica (i); ello nos permitirá clarificar el tipo de legislación (ii) y el interés de la razón (iii) en la filosofía de la historia; con lo que esperamos mostrar que, a partir de

7 Hermann Cohen (1842-1918), filósofo alemán, fundador, entre otros, de la neokantiana Escuela de Marburgo. Es célebre por sus comentarios sobre Kant, en especial su Theorie der Erfahrung (1871). La Escuela centró sus estudios en la teoría del conocimiento de Kant.

8 Johann Gottfried von Herder (1744-1806), Ideas para una filosofía de la historia de la humanidad (1784-1791). Esta obra pretende demostrar que la naturaleza y la historia humana obedecen las mismas leyes y que, con el tiempo, las formas humanas antagónicas se reconciliarán.

9 Ver: UREÑA, Enrique. La crítica kantiana de la sociedad y de la religión. Madrid: Técnos, 1979.

${ }^{10}$ IMAZ, Eugenio. "Prólogo". En: KANT, Immanuel. La filosofía de la historia. México: F. C. E., 1979. 
la dialéctica entre naturaleza y libertad (iv), Kant puede superar algunas antinomias generadas por el abismo entre la razón teórica y la razón práctica, entre ellas, la relación entre legalidad y moralidad (v).

\section{El sistema de la razón pura}

Para situar en forma apropiada la reflexión sobre la historia en la estructura del sistema y su relación con las demás partes del todo, es necesario dar una mirada a "La arquitectónica de la razón pura" 11 que se encuentra al final de la primera Crítica, en donde Kant esboza todo su sistema crítico, insistiendo en que, para alcanzar los fines más esenciales de la razón, nuestros conocimientos no deben constituir una rapsodia sino formar un sistema, esto es, una diversidad de conceptos bajo una idea. Se trata de encontrar la articulación del todo, bajo la unidad del fin al que todas las cosas se refieren, de tal forma que a priori se pueda determinar tanto la amplitud de los diversos conocimientos como el lugar respectivo de las partes en el todo.

La tarea que se propuso Kant fue dar unidad al conocimiento humano, superando la apariencia de una rapsodia de múltiples construcciones que se ensamblan en una forma técnica y no bajo la idea de una luz clara que pueda mostrar su unidad de acuerdo con los fines de la razón. Los sistemas intentados, aunque todos ellos hayan tenido su esquema, han resultado incompletos y dan la impresión de una mera confluencia de conceptos reunidos. No obstante, la gran cantidad de material reunido que puede ser tomado de los viejos edificios caídos le permite a Kant, según su opinión, esbozar la arquitectónica de todo conocimiento derivado de la razón pura. ${ }^{12}$

La arquitectónica, para seguir utilizando esta palabra de la que gustaba Kant, tiene como eje la "revolución copernicana del pensamiento", expresión que utiliza en el prólogo a la segunda edición de la Crítica de la razón pura para explicarnos la forma como le ha sido posible a la lógica, la matemática y la física encontrar el camino seguro de la ciencia; al tiempo que para proponer una revolución copernicana para la metafísica, puesto que, a pesar de ocuparse de nuestros más importantes anhelos de saber, anda a tientas, sin encontrar su camino seguro.

${ }^{11}$ KANT, Immanuel. "La arquitectónica de la razón pura”. En: Crítica de la razón pura. Madrid: Alfaguara, 1989, pp. 647-658. (A 832-851, B 860-879).

12 Ibid., p. 649, (A 835/ B 863). 
Dicho método parte de la premisa de que «sólo conocemos de las cosas lo que nosotros mismos ponemos en ellas» ${ }^{13}$. De esta forma las ciencias han logrado conocer algo a priori sobre la naturaleza del objeto, puesto que son los objetos los que deben conformarse y regirse por nuestra facultad de conocer.

La arquitectónica del sistema se sostiene sobre la distinción entre conocimiento empírico y conocimiento racional. Mientras que el conocimiento empírico tiene sus fuentes a posteriori en la experiencia y por ser cognitio ex datis sus proposiciones sólo llegan a ser generalidades inductivas; el conocimiento racional es cognitio ex principis, lo que quiere decir que extrae su conocimiento de las fuentes universales a priori de la razón con independencia de la experiencia, por lo que sus proposiciones son universales y necesarias.

Todos los conocimientos racionales se dividen en dos: conocimientos por conceptos y conocimientos por construcción de conceptos. Mientras el conocimiento filosófico es un conocimiento racional derivado de conceptos, el conocimiento matemático es un conocimiento obtenido por construcción de los conceptos. Construir un concepto significa presentar la intuición a priori que le corresponde. Los juicios matemáticos son posibles porque sus conceptos son representados en el espacio y en el tiempo. ${ }^{14}$

Para Kant la filosofía, dado que no puede representar sus conceptos en el espacio-tiempo, es la mera idea de una ciencia posible que no está dada en concreto en ningún lugar. Es por esto que no es posible aprender filosofía -a no ser desde un punto de vista histórico- sólo se puede aprender a filosofar. Según Kant, de acuerdo a un concepto cósmico, es decir, con sentido de orden, y no a un concepto de escuela: "la filosofía es la ciencia de la relación de todos los conocimientos con los fines esenciales de la razón humana y el filósofo es un legislador de esa misma razón, no un artífice de ella. En tal sentido demostraría gran arrogancia el llamarse a sí mismo filósofo y pretender igualarse a un prototipo que sólo se halla en la idea."15

Dos cosas importantes cabe destacar para el tema que nos ocupa. En primer lugar, al filósofo le corresponde unir y utilizar todos los conocimientos para

${ }^{13}$ Ibid., p. 21, (B XVIII)

${ }^{14}$ Sobre la distinción entre el conocimiento filosófico y el matemático, véase: Ibid., pp. 574 y ss. (A713 y ss. / B741 y ss.)

${ }^{15}$ Ibid., p. 651 (A 839 / B 867) 
promover los fines de la razón humana. En segundo lugar, el filósofo es un legislador. Con base en esto podemos afirmar que es adecuada la expresión "filosofía de la historia" para referirnos a la reflexión kantiana sobre la historia. Dado que no se interesa en la descripción de hechos o acontecimientos, no es la suya una historia empírica, ni siquiera una historia razonada de instituciones y mentalidades como la que Voltaire pretendía. Kant buscaba comprender los "hilos conductores" de la historia, para descubrir un orden, un curso regular, o la intención de la naturaleza:

"Vamos a ver si conseguimos encontrar unos cuantos hilos conductores para una tal historia, y dejaremos al cuidado de la naturaleza que nos traiga al hombre que la quiera concebir ateniéndose a ellos, que así produjo un Kepler que sometió de manera inesperada los movimientos excéntricos de los planetas a leyes determinadas; y así, también un Newton que explicó estas leyes por una causa natural general." 16

Lo que Kant quiere no es hacer una descripción de hechos, lo que él pretende como filósofo es legislar, esto es, alcanzar unos principios que den orden al aparente caos de la historia, sonsacándole un sentido y haciéndola profetizar. No obstante surge la pregunta: ¿Qué tipo de legislación le corresponde a la filosofía de la historia: leyes de la libertad o leyes de la naturaleza?

\section{El tipo de legislación de la filosofía de la historia}

El sistema kantiano, si bien tiene al destino del hombre como único bien supremo, posee dos tipos de legislación. "La legislación de la razón humana (filosofía) posee dos objetos, naturaleza y libertad, y, consiguientemente, incluye tanto la ley de la naturaleza como la ley moral, primero en dos sistemas distintos y finalmente, en un único sistema filosófico. La filosofía de la naturaleza se refiere a todo lo que es; la filosofía moral a lo que debe ser."17

La filosofía de la naturaleza es la legislación cuyo objeto es la naturaleza y el uso que se hace de la razón en ella es teórico, el cual es expuesto en la "Analítica trascendental” que establece las bases seguras del conocimiento científico al limitar su ámbito a objetos de la experiencia posible. El conocimiento es posible

${ }^{16}$ KANT, Immanuel. "Idea de una historia universal en sentido cosmopolita". En: Filosofía de la historia. México: F. C. E., 1979.

${ }^{17}$ KANT, Immanuel. Crítica de la razón pura. Op., cit., p. 652. (A 840 / B 868). 
gracias a la conjunción de los datos de la intuición sensible con la actividad sintética del sujeto cognoscente. La razón teórica tiene la dependencia del material sensible como condición sine qua non para la producción de conocimientos. La legislación de la razón teórica produce leyes de la naturaleza, leyes de todo lo que es, leyes que, como la ley de la causalidad, determinan la naturaleza en forma absoluta.

Sin embargo, la razón no se conforma con este límite estrecho del conocimiento, pues sus intereses están más allá. Ese intento especulativo de atribuir al uso teórico de la razón un alcance suprasensible, arrastra a la razón al fatídico terreno de la ilusión -como el ejemplo de la paloma que cree que abandonado el aire podría volar mejor- entrando en contradicción consigo misma. A la crítica de esta ilusión la llama Kant "Dialéctica trascendental” y constituye una crítica de la metafísica dogmática que cree poder conocer de Dios, la inmortalidad del alma y la finitud o infinitud del cosmos, partiendo meramente de conceptos o principios, sin haber examinado el modo ni el derecho con el que llega a ellos. Por ello Kant insiste en que la utilidad principal de la crítica es negativa, "nos advierte que jamás nos aventuremos a traspasar los límites de la experiencia con la razón especulativa". ${ }^{18}$

En efecto, las restricciones a las posibilidades del conocimiento expuestas por el fundamento de éste en la intuición sensible, deja fuera de alcance las preguntas metafísicas que son las fundamentales para la razón humana: Dios, la inmortalidad del alma y la finitud o infinitud del cosmos. Sin embargo, Kant le abre otra ventana a este tipo de preguntas: «no obstante hay que dejar siempre a salvo, y ello ha de tenerse en cuenta, que aunque no podamos conocer esos objetos, sí ha de sernos posible, al menos pensarlos». ${ }^{19}$ La salida que nos da Kant a esa inclinación natural de la razón a la metafísica, es el uso de una razón no cognoscitiva, no una razón teórica que funciona con conceptos como el de causalidad, sino una razón práctica que se oriente por ideas como libertad, justicia y solidaridad. "La razón es arrastrada por una tendencia de su naturaleza a rebasar su uso empírico y a aventurarse en un uso puro, mediante simples ideas, más allá de los últimos límites de todo conocimiento, a la vez que no encontrar reposo mientras no haya completado su curso en un todo sistemático y subsistente por sí mismo." 20

${ }^{18}$ Ibid., p. 24 (B XXV).

${ }^{19}$ Ibid., p. 25 (B XXVII).

${ }^{20}$ Ibid., p. 625 (A 798 / B 826). 
En "El canon de la razón pura encontramos el giro práctico; ya que el uso especulativo nos cierra el camino a los afanes de la razón pura, debemos esperar «que quizá tenga más suerte en el único camino que le queda todavía, el del uso práctico». ${ }^{21}$ Para Kant, práctico es todo lo que es posible mediante libertad. El uso práctico no se refiere a la determinación de un objeto, sino a convertir éste en realidad mediante la acción referida a los otros, por ello sus leyes establecen lo que debe suceder aunque nunca suceda. La diferencia fundamental estriba en que el uso teórico busca el conocimiento de lo que hay, mientras que en el uso práctico se trata de la producción de objetos que corresponda a nuestra representación ideal. La razón es verdaderamente práctica cuando sus principios de determinación a la acción responden a sus fines propios, y no a fines instrumentales empíricos o a inclinaciones sensibles. Tales principios del uso práctico de la razón pura son las leyes morales, y solo ellos constituyen el canon o uso correcto de la razón.

Llegados a este punto conviene preguntarnos si la filosofía de la historia pertenece al uso teórico o al uso práctico de la razón. La respuesta no es tan sencilla y no son pocas las situaciones de incertidumbre que genera. Si hacemos énfasis en el comienzo de la Idea de una historia universal desde el punto de vista cosmopolita nos encontramos con que la propuesta de Kant es la posibilidad de una historia como ciencia de fenómenos: “... cualquiera que sea el concepto que, en un plano metafísico, tengamos de la libertad de la voluntad, sus manifestaciones fenoménicas, las acciones humanas se hayan determinadas, lo mismo que los demás fenómenos naturales, por las leyes generales de la naturaleza.",22

Asumiendo esto al pie de la letra, se trataría de buscar leyes generales de la naturaleza, es decir, una legislación del uso teórico. Kant estaría buscando entonces las condiciones de posibilidad de la ciencia histórica como un saber fenoménico. Sin embargo, la ciencia histórica todavía no estaría cimentada, y por lo tanto, no constituiría un factum como el de la ciencia física. Se propone entonces encontrar «unos hilos conductores para una tal historia» dejando a la naturaleza el cuidado de hacer aparecer un Kepler o un Newton que explique el movimiento de los fenómenos según leyes determinadas. Una especie de

${ }^{21}$ KANT, Immanuel. “Canon de la razón pura”. En: Crítica de la razón pura. Op. Cit., p. 624. (A 795 / B 823).

${ }^{22}$ KANT, Immanuel. "Idea de una historia universal en sentido cosmopolita”. Op. Cit., p. 39. 
Newton del mundo histórico, así como, según él, Rousseau es el Newton del mundo moral.

Pero de otro lado, si el énfasis lo ponemos en esa estructura evolutiva que tiene por finalidad la paz perpetua, y si tenemos en cuenta el título mismo de su ensayo sobre la historia, Idea de una historia universal en sentido cosmopolita, su reflexión se sitúa en el nivel de la idea, es decir, en el nivel que la dialéctica definió como un concepto que está formado por nociones que rebasan la posibilidad de la experiencia. Se trataría entonces, no de leyes de lo que es, sino de leyes de lo que debería ser. ${ }^{23}$ Bien tentados estamos de decir que se trata de dos momentos. En el primero se miraría la historia hacía atrás en el tiempo, legislando con leyes naturales sobre lo que es y, en un segundo momento, tratándose de la historia hacia el futuro, legislando de acuerdo a leyes de la libertad ya que no se trataría de una historia natural humana, sino de una historia de las costumbres. Pero ésta es una salida bastante incómoda ya que rompería con la unidad de estos textos. Rodríguez Aramayo ha propuesto una hipótesis plausible: “(...) bajo el seudónimo de naturaleza, se esconde la identidad real del auténtico guionista, que no es otro sino el filósofo de la historia". ${ }^{24}$ El filósofo de la historia en definitiva es quien traza un sentido teleológico de la historia y desde él desenvuelve la trama de las acciones humanas, él reclutaría la insociable sociabilidad para ponerla al servicio de su guión. En otras palabras, una versión más de lo que Hegel llamó «la astucia de la razón».

Por nuestra parte ensayaremos resolver el problema partiendo del interés de la razón en la filosofía de la historia. Este camino nos permitirá pensar la filosofía de la historia como una prolongación natural del pensamiento de Kant, con la que pretende superar el abismo entre la razón teórica y una razón práctica excesivamente formal, a partir de una nueva dialéctica entre naturaleza y libertad, logrando con ello resolver la supuesta antinomia entre legalidad y moralidad.

${ }^{23}$ En ese sentido Kant sería un precedente, como tantas veces ha sido invocado, de las ciencias de la cultura o de las ciencias de la discusión como se les ha llamado ahora utilizando una expresión de Habermas. Ver: HOYOS, Guillermo y VARGAS, Germán. La teoría de la acción comunicativa como nuevo paradigma de investigación en ciencias sociales. Las ciencias de la discusión. Bogotá: ICFES, 1996.

${ }^{24}$ RODRÍGUEZ ARAMAYO, Roberto. "El auténtico sujeto moral de la filosofía kantiana de la historia." En: Kant después de Kant. A.A.V.V., Madrid: Tecnos, 1989, pp. 234-243. 


\section{El interés de la razón en la filosofía de la historia}

En "El canon de la razón pura” Kant nos presenta formuladas en tres preguntas todos los intereses de la razón, tanto los especulativos como los prácticos. La primera pregunta «¿qué puedo saber?» es meramente especulativa y ha sido resuelta satisfactoriamente en la "Analítica trascendental": se puede saber de todo lo que se da en la experiencia, aunque sólo de lo que se da en la experiencia. La segunda cuestión “¿qué debo hacer?" es meramente práctica y es una pregunta moral cuya respuesta es: haz aquello mediante lo cual te haces digno de ser feliz. Y, la tercera cuestión "¿qué puedo esperar si hago lo que debo?” es práctica y teórica a un tiempo, "de modo que lo práctico nos lleva, sólo como hilo conductor, a dar un respuesta a la cuestión teórica y, si ésta se eleva, a la cuestión especulativa". ${ }^{25}$ La tercera pregunta encuentra su respuesta en la filosofía de la religión, pero también en ella se encuentra la respuesta última al sentido del hombre en la historia y por tanto constituye el interés de la filosofía de la historia. Dado que se trata de una pregunta teórica y práctica a la vez, su respuesta explícita nos conduciría a un estudio de la relación entre la Crítica de la razón pura y la Crítica de la razón práctica y, desde luego, tendríamos que mirar la relación con la Crítica del Juicio en la que Kant pretende zanjar el abismo entre las dos primeras. Todo esto obviamente escapa a nuestro trabajo. Sin embargo, ateniéndonos al "Canon de la razón pura" la respuesta a la pregunta ¿qué puedo esperar, si me hago digno de ser feliz?, lleva a Kant a formular el ideal del bien supremo como una idea de la razón pura, como unidad en la que cada cual puede esperar la felicidad exactamente en la medida en que se haya hecho digno de ella. Dicho ideal impone la necesidad de aceptar dos supuestos como principios de la razón pura: Dios y la vida futura.

En la perspectiva de los trabajos sobre la filosofía de la historia, nos encontramos con un pensamiento práctico mucho más secularizado. Llevando la filosofía moral del plano individual a la filosofía de la historia en el plano de la especie, nos encontramos no con Dios, sino con un progreso asintótico hacia la paz perpetua. Así, Dios aparece como una hipótesis heurística, como un nombre más para la razón, "Dios no es un ser exterior a mí. Dios es la razón éticopráctica autolegisladora” ${ }^{26} \mathrm{La}$ idea del progreso asintótico hacia la paz perpetua

${ }^{25}$ KANT, Immanuel. Crítica de la razón pura. Op. Cit., p. 630. (A 806).

${ }^{26}$ KANT, Immanuel. La religión dentro de los límites de la mera razón. Madrid: Alianza, 1979. 
abre el formalismo ético kantiano a la perspectiva de una utopía histórica, no sólo como una posibilidad, sino que su búsqueda constituye un deber moral. Es por esto que podemos afirmar que el formalismo ético encuentra su continuidad en la filosofía de la historia porque, según afirma Kant: «un albedrío que sabe cómo, pero no hacia donde tiene que obrar, no puede bastarse».

Hasta el momento hemos tratado de mostrar que la reflexión sobre la historia, con todo y las aporías que pueda presentar, constituye el desarrollo natural del pensamiento kantiano, que sin abandonar su filosofía crítica ni su sistema, constantemente pretende llevar hasta el límite todas las posibilidades. Como señala Agnes Heller: "Más bien cabría parangonar este sistema con una catedral gótica que aun habiendo sido erigida de una vez obedeciendo a la inspiración de una idea artística, no por ello deja de experimentar cambios en tiempos posteriores." 27

\section{La dialéctica entre naturaleza y libertad}

El interés que mueve la filosofía de la historia es el de descubrir un hilo de racionalidad en el decurso de una historia irracional y caótica, que como nos lo dice Kant "obliga a apartar de ella los ojos para no cargarse con un vicio más, a saber el odio a la humanidad». ${ }^{28}$ Sin embargo, en la Idea de una historia universal en sentido cosmopolita Kant nos advierte que así los pueblos y los individuos busquen sus propios intereses y fines, en realidad siguen y fomentan una finalidad de la naturaleza.

"La historia del género humano se puede considerar en general, como la realización de un plan oculto de la naturaleza encaminado al establecimiento de una constitución estatal interior y exterior perfecta, como la única situación posible en la que la naturaleza puede hacer que se desarrollen plenamente todas las disposiciones que ella ha puesto en la humanidad. $" 29$

Aparece aquí como un desarrollo lógico del plan de la naturaleza el establecimiento de una estructura legal que permita una convivencia racional de

los hombres en sociedad. Nos interesa resaltar que esa constitución aparentemente

${ }^{27}$ HELLER, Agnes. “La primera y la segunda ética de Kant”. En: Crítica de la ilustración. Barcelona: Península, 1984, p. 22.

${ }^{28}$ KANT, Immanuel. La religión dentro de los límites de la mera razón. Op., Cit. B29.

${ }^{29}$ KANT, Immanuel. "Idea de una historia universal en sentido cosmopolita”. Op., Cit. p. 49. 
es el resultado de la naturaleza y no de la libertad humana. Da la impresión de que el hombre fuera un títere dejado a la suerte de una naturaleza astuta que utiliza la lucha de los hombres para lograr sus propósitos. El motor de la insociable sociabilidad humana, le sirve a la naturaleza para conducir al hombre hacia el ideal del mundo moral. Miremos como lo presenta Kant:

"El medio de que se sirve la naturaleza para lograr el desarrollo de todas sus disposiciones es el ANTAGONISMO de la misma en sociedad, en la medida que ese antagonismo se convierte a la postre en la causa de un orden legal de aquellas. Entiendo en este caso por antagonismo la insociable sociabilidad de los hombres, es decir, su inclinación a formar sociedad que, sin embargo, va unida a una resistencia constante que amenaza perpetuamente con disolverla." ${ }^{30}$

No obstante la contradicción entre la astuta naturaleza y la libertad humana es sólo aparente. Kant no sacrifica la libertad humana. Lo que tenemos es una estrecha e interdependiente relación, que podríamos llamar dialéctica, entre naturaleza y libertad. Para comprender la filosofía de la historia es necesario distinguir dos tipos de fines y dos tipos de progresos. Por un lado, la finalidad de la naturaleza es el desarrollo de un organismo que busca la adecuada y completa plenitud de las disposiciones naturales, esta finalidad la logra la "astuta naturaleza" mediante el motor de la insociable sociabilidad. Por otro lado, para el filósofo de Königsberg el hombre es esencialmente un ser libre, capaz de darse así mismo sus propios fines, los cuales no son determinados por sus disposiciones naturales, sino por su determinación a la moralidad. Esto permite hablar de una finalidad práctica, que orientada por los ideales de la razón busca la realización del hombre como ser moral. El progreso en la dimensión moral ya no tiene como motor la insociable sociabilidad, sino que su dinamismo está dado por el proceso de ilustración creciente tanto del individuo como del género:

"Y así transcurren los primeros pasos serios de la rudeza a la cultura, que consiste propiamente en el valor del hombre; los talentos van desarrollándose poco a poco, se forma el gusto y, mediante una continuada ilustración, se convierte el comienzo en una manera de pensar que, a la larga, puede cambiar la ruda disposición natural para la diferenciación moral en principios prácticos determinados y, de este modo, también la coincidencia a formar sociedad, patológicamente provocada en un todo moral." 31

${ }^{30}$ Ibid. p. 46.

${ }^{31}$ Ibid., p. 47. 
Lo que resulta claro es que la idea del todo moral aparece como una idea regulativa y la filosofía de la historia como prolongación de la ética, en la medida que nuestro deber está comprometido con la búsqueda de esa utopía histórica. ${ }^{32}$

\section{Derecho y moral}

La dinámica de la insociable sociabilidad nos obliga a salir de ese estado de naturaleza y evitar la guerra por medio de dos progresos humanos: el derecho y la moral. Por un lado, una organización legal obliga al hombre a respetar la ley y ser buen ciudadano, así no sea un hombre moralmente bueno; se trata de las acciones externas de los hombres y de las instituciones que ellos forman. Por otro lado, el progreso moral que se refiere a la autonomía de los individuos con respecto a su obrar, implica la ilustración a la que aspira todo individuo: «a la salida del hombre de su condición de menor de edad, de la cual él mismo es culpable». ${ }^{33}$

La tarea del derecho y la moral en la historia la encontramos expresada claramente por Kant en su texto La paz perpetua, en el que señala que dado que el estado de naturaleza es la lucha de todos contra todos en el que la guerra campea, el estado de paz debe, por tanto, ser instaurado. ${ }^{34} \mathrm{El}$ derecho tiene la tarea de hacer surgir la comunidad, saliendo del estado de naturaleza para construir una sociedad civil mediante un contrato originario. Esto es un imperativo de la razón, un deber ético. También en la Metafísica de las costumbres señala que "la razón práctico-moral formula en nosotros su veto irrevocable: no debe haber guerra". ${ }^{35}$

En la teoría del derecho Kant utiliza su método de deducción trascendental. Método que consiste en partir de un factum de la ciencia, sobre el que hay que

\footnotetext{
32 Tendríamos entonces, como sugiere Aramayo, el embrión de una crítica de la razón ucrónica, con un imperativo elpidiológico que nos impelería a obrar "como si" en la esperanza de que nuestros esfuerzos terminen por contribuir a la utopía histórica. RODRÍGUEZARAMAYO, Roberto. Crítica de la razón ucrónica. Estudio en torno a las aporías morales de Kant. Madrid: Técnos, 1992.

${ }^{33}$ KANT, Immanuel. "Respuesta a la pregunta: ¿qué es la ilustración? En: Argumentos, No. 14-17, Bogotá, 1986, p. 30.

${ }^{34}$ KANT, Immanuel. La paz perpetua. México: Porrúa, 1983, p. 221.

${ }^{35}$ KANT, Immanuel. Metafísica de las costumbres. Barcelona: Altaya, 1994, p. 195.
} 
mostrar y formular los conceptos puros que exponen sus condiciones de posibilidad. Tratándose de la ciencia del derecho, el factum es el derecho positivo y sus principios están contenidos en lo que Kant llama derecho natural. El derecho positivo sirve sólo de punto de partida y de hilo conductor para la investigación de los principios y fundamentos que sirven de supuesto a toda legislación futura. La validez de los principios no depende de la realidad del derecho positivo que se haya tomado accidentalmente para la investigación, pues su validez sería sólo relativa. Los principios puros del derecho no derivan de la experiencia del derecho positivo, sino que, por el contrario, los principios puros son el fundamento y la condición de posibilidad de todo derecho positivo. Los principios de una teoría pura del derecho, que Kant llama derecho natural, se originan a priori en la razón. Por supuesto, Kant no utiliza la expresión "derecho natural" en el sentido de un derecho de la naturaleza, como si hiciera parte de la legalidad natural o de la naturaleza biológica del hombre. No, para Kant el derecho se guía por la legalidad ética y hace parte de la racionalidad práctica. La expresión equívoca de "derecho natural" es, en Kant, equivalente a "derecho racional".

El concepto de razón significa, para Kant, legalidad en general. Por eso, cuando define el derecho como "el conjunto de condiciones bajo las cuales el arbitrio de uno puede conciliarse con el arbitrio del otro según una ley universal de la libertad", 36 el arbitrio a que se refiere no tiene que ver con el gusto de los individuos, sino con la razón pura. En efecto, Kant presenta el arbitrio como una facultad determinable, más referida a la acción que al fundamento que la determina. Cuando es determinada por la inclinación se denomina arbitrio bruto y cuando resulta determinada por la razón pura se denomina arbitrio libre. El que el arbitrio sea independiente de los móviles sensibles expresa el concepto negativo de libertad; mientras que, cuando fundamenta su acción en una ley universal de la razón, estamos frente al concepto positivo de libertad.

Para Kant el derecho tiene su fuente y criterio en el "contrato originario". Con la noción de "contrato originario" Kant no se está refiriendo a un hecho histórico, sino a una idea regulativa que cumple las veces de fuente y criterio del derecho. El contrato es una fuente del derecho porque representa la idea de una voluntad unida del pueblo que se erige en ley universal; en ese sentido, todo derecho parte sistemáticamente de esta idea, aunque éste no sea el comienzo del derecho. Lo

${ }^{36}$ Ibid., p. 39. 
que aquí importa no es si un pueblo o un individuo dan su consentimiento a una ley en concreto, sino que pudieran dar su adhesión prescindiendo de contingencias individuales o históricas. Como lo expresa con claridad suprema Kant:

No necesitamos en modo alguno suponer tal contrato -incluso, no sería posiblecomo un 'hecho' (llamado contractus originarius o pactum sociale), entendido como la coalición de cada voluntad particular y privada con la social y pública de un pueblo (con el fin de una legislación meramente jurídica). (...) Entretanto, es una mera idea de la razón, pero que tiene indudable realidad (práctica), a saber, la de obligar a cada legislador para que dé sus leyes tal como si éstas pudiesen haber nacido de la voluntad reunida de todo un pueblo y para que considere a cada súbdito, en cuanto quiera ser ciudadano, como si hubiera estado de acuerdo con una voluntad tal. Esto es, en efecto, la piedra de toque de la juridicidad de una ley pública capaz de regir para todos. ${ }^{37}$

El contrato originario, en tanto idea de la razón, determina lo que es el derecho; como criterio o piedra de toque, determina si la ley promulgada por el legislador es justa. Lo es, en la medida en que el legislador se pregunta, para promulgarla, si un pueblo se podría dar a sí mismo una ley como la que propone. Al establecer el contrato originario, se llega a una sociedad civil que administra el derecho en general, a partir de una constitución civil.

Sin embargo, el que un pueblo pueda organizarse con una constitución civil perfecta depende, a su vez, del establecimiento de una relación legal entre los Estados. En efecto, para Kant, los Estados, sin una ley externa a la que se sometan, pueden considerarse como individuos en estado de naturaleza, cuya convivencia está constantemente amenazada por la guerra. Por ello, para encontrar seguridad y paz, los Estados se ven compelidos a dejar su salvaje libertad y a buscar tranquilidad en una relación legal. La propuesta kantiana es la de establecer un derecho de gentes fundado en una federación de Estados libres, "en la que aún el Estado más pequeño puede esperar su seguridad y su derecho no de su propio poderío o de su propia decisión jurídica, sino únicamente de esa gran federación de naciones (Foedus Amphictyonum), de una potencia unida y de la decisión según leyes de la voluntad unida."38

Los principios constitutivos del estado jurídico son libertad, igualdad y

${ }^{37}$ KANT, Immanuel. "Acerca de la relación entre teoría y práctica en el derecho político (Contra Hobbes)”, en: Filosofía de la historia. Buenos Aires: Nova, 1964, p. 167.

${ }^{38}$ KANT, Immanuel. "Idea de una historia universal en sentido cosmopolita”. Op., Cit. p. 53. 
autonomía. La libertad jurídica es definida como "la facultad de no obedecer a las leyes exteriores sino en tanto en cuanto he podido darles mi consentimiento." ${ }^{39}$ La igualdad jurídica en un estado se define como una relación entre los ciudadanos, según la cual "nadie puede imponer a otro una obligación jurídica sin someterse él mismo también a la ley y poder ser, de la misma manera, obligado a su vez." ${ }^{40}$ La autonomía jurídica es entendida como colegislación. Para Kant estos tres principios, intrínsecamente relacionados, son ideas directrices que fundamentan toda comunidad jurídica.

Kant hace esfuerzos por realizar una deducción trascendental de los principios puros del derecho, a partir de la razón práctica y de su ley universal. Es cierto que no aplica la deducción trascendental de la misma forma que lo hace con las categorías del entendimiento en la primera "Crítica"; sin embargo, al mostrar que hay conceptos que son condiciones del Estado y del derecho, y que no dependen de condicionamientos empíricos, está asumiendo la actitud y el pensamiento trascendental. ${ }^{41}$ Kant desecha la tesis de que los principios del derecho sean producidos por la legislación de un Estado, indica, por el contrario, que son leyes según las cuales es posible la organización de todo Estado. Su deducción consiste justamente en mostrar que los conceptos de libertad, igualdad y autonomía son condiciones necesarias de la posibilidad del Estado y de toda legislación positiva.

El derecho y la moral se distinguen menos por los deberes que imponen, que por los móviles que ligan a cada legislación. El móvil de la legislación jurídica puede ser distinto a la idea de deber, mientras que el móvil de la moral es la idea misma del deber. El derecho regula la relación exterior de los individuos; la moral plantea deberes para con los otros y para consigo mismo. Para el derecho los motivos están fuera de interés y son accidentales a la hora de evaluar la conducta jurídica; para la moral lo decisivo son los motivos de la acción, la verdadera acción moral es la que se realiza por deber. Kant distingue tajantemente entre la comunidad jurídica y la comunidad moral. Mientras el derecho tiene el propósito de hacer buenos ciudadanos - lo que puede lograr

${ }^{39}$ KANT, Immanuel. La paz perpetua. Op., Cit. p. 222. (Nota a pie de página).

${ }^{40}$ Ibid., p.222.

${ }^{41}$ La profesora Cortina sostiene, apoyada en F. Kaulbach, que el método trascendental es, más que una técnica minuciosa, una actitud, la posibilidad de adoptar una perspectiva. Ver: CORTINA, Adela, "Estudio introductorio" en: KANT, Immanuel. Metafísica de las costumbres. Op., Cit. p. XXVI. 
hasta con un "pueblo de demonios"-,${ }^{42}$ la moral pretende hacer buenas personas. AlEstado, como expresión de juridicidad, le está negada la posibilidad de legislar en el interior de los ciudadanos, ámbito reservado a la legislación moral. Para el Estado es importante que los ciudadanos cumplan las leyes jurídicas, pero le es indiferente que los ciudadanos sean también buenos moralmente.

No obstante, también existen relaciones complementarias entre derecho y moral. En realidad se trata de dos sistemas normativos cuyas legislaciones ayudan a cumplir con una tarea común: alcanzar la paz. La legalidad y la moralidad, como legislaciones del derecho y la moral, son en realidad dos progresos inseparables. La perfecta legalidad sólo es posible si está apoyada en la moralidad de los individuos de esta sociedad. La legalidad aparece como una condición para la moralidad, pues sólo un estado civil pone fin al estado de naturaleza en el que cada quien obra a su antojo, e inicia el camino hacia una paz duradera. A su vez, la legalidad tiene como legitimidad el estar propiciando el ideal moral humano. La constitución estatal se apoya en definitiva sobre la moralidad del pueblo.

La relación de mutua dependencia entre legalidad y moralidad la encontramos expresada en esa confianza que tenía Kant en el desarrollo de la ilustración, si se contaba con una república que permitiera "la más inocente de todas las libertades: el uso público de la razón” y, a su vez, la confianza en que ese público, si se le dejaba en libertad de discutir, llegaría a la ilustración y nos conduciría hasta la configuración de la sociedad como un todo moral. Como afirma Kant, refriéndose a la relación entre libertad de pensamiento y libertad del uso público de la razón:

Algunos dicen: el poder superior nos puede quitarla libertad de hablar o la de escribir, pero la libertad de pensar no nos la puede quitar nadie por ningún medio. Pero ¿cuánto y cuan correctamente podríamos pensar, si no pudiésemos hacerlo en compañía de otros con los que tuviésemos un intercambio de pensamientos e ideas? por lo tanto, se puede decir muy bien, que aquel poder externo que nos prive de comunicar públicamente nuestro pensamiento, nos priva también de la libertad de pensar; de esa única áncora de salvación. ${ }^{43}$

42 "El problema del establecimiento de un Estado tiene solución, por muy extraño que parezca, aun cuando se trate de un pueblo de demonios; basta con que éstos posean entendimiento." KANT, Immanuel, La paz perpetua, Op., Cit. p. 233.

${ }^{43}$ KANT, Immanuel. “QQué significa orientarse en el pensamiento?”, G. S., vol. VIII. Citado por Lucien Goldmann, Introducción a la filosofía de Kant. Buenos Aires: Amorrortu, 1974, p.115. 


\section{Conclusiones}

Los ensayos socio-históricos en los que Kant se ocupó del Estado, la historia, la Ilustración y la paz, configuran una filosofía de la historia. Dicha filosofía de la historia hace parte del sistema de la filosofía crítica. Con ella, Kant pretende legislar, esto es, alcanzar unos principios que den orden al aparente caos de la historia, sonsacándole un sentido y haciéndola profetizar.

En la filosofía de la historia Kant presenta una dialéctica entre naturaleza y libertad, que le permite superar algunas antinomias que le había dejado el abismo entre una razón teórica y una razón práctica excesivamente formal. En ese proyecto, el derecho y la moral, como dos tipos de sistemas normativos, tienen la función histórica de ayudar a superar el permanente conflicto que genera la insociable-sociabilidad propia de la condición humana. Derecho y moral nos ayudan a salir del estado de naturaleza.

Legalidad y moralidad, como legislaciones del derecho y la moral, son dos progresos inseparables que ayudan a cumplir con una tarea común: alcanzar la paz. Legalidad y moralidad son legislaciones complementarias. La legalidad es una condición para la moralidad, pues sólo un estado civil pone fin al estado de naturaleza en el que cada quien obra a su antojo, e inicia el camino hacia una paz duradera. A su vez, la legalidad tiene como legitimidad el estar propiciando el ideal moral humano. La constitución estatal se apoya en definitiva sobre la moralidad del pueblo.

\section{Bibliografía}

CORTINA, Adela. "Estudio introductorio a la Metafísica de las costumbres" en: KANT, Immanuel. Metafísica de las costumbres. Barcelona: Altaya, 1994.

GOLDMANN, Lucien. Introducción a la filosofía de Kant. Buenos Aires: Amorrortu, 1974.

HELLER, Agnes. "La primera y la segunda ética de Kant". En: Crítica de la ilustración. Barcelona: Península, 1984.

HOYOS, Guillermo y VARGAS, Germán. La teoría de la acción comunicativa como nuevo paradigma de investigación en ciencias sociales. Las ciencias 
de la discusión. Bogotá: ICFES, 1996.

IMAZ, Eugenio. "Prólogo". En: KANT, Immanuel. La filosofía de la historia. México: F. C. E., 1979.

KANT, Immanuel. "Idea de una historia universal desde el punto de vista cosmopolita". En: Filosofía de la historia. México: F. C. E., 1979.

KANT, Immanuel. "Respuesta a la pregunta: ¿qué es la ilustración?”. En: Argumentos, Bogotá, No. 14-17, 1986, pp. 28-44.

KANT, Immanuel. La contienda de las facultades de filosofía y teología. Madrid: Consejo Superior de Investigaciones Científicas/Debate, 1992.

KANT, Immanuel. La religión dentro de los límites de la mera razón. Madrid: Alianza, 1969.

KANT, Immanuel. "Acerca de la relación entre teoría y práctica en el derecho político (Contra Hobbes)", en: Filosofía de la historia. Buenos Aires: Nova, 1964.

KANT, Immanuel. La paz perpetua. México: Porrúa, 1972.

KANT, Immanuel. Metafísica de las costumbres. Barcelona: Altaya, 1994.

KANT, Immanuel. Crítica de la razón pura. Madrid: Alfaguara, 1989.

RODRÍGUEZ A., Roberto. "El auténtico sujeto moral de la filosofía kantiana de la historia." En: Kant después de Kant. A.A.V.V., Madrid: Tecnos, 1989, pp. 234-243.

RODRÍGUEZ A. Roberto. Crítica de la razón ucrónica. Estudio en torno a las aporías morales de Kant. Madrid: Técnos, 1992.

UREÑA, Enrique. La crítica kantiana de la sociedad y de la religión. Madrid: Técnos, 1979. 